\title{
UMA TRADUÇÃO DA TRADIÇÃO EM O PÁTIO DAS SOMBRAS, DE MIA COUTO
}

\section{TRANSLATION OF TRADITION IN O PÁTIO DAS SOMBRAS, DE MIA COUTO}

Vera Lúcia da Rocha Maquêa ${ }^{1}$

\begin{abstract}
Resumo: Nesse artigo será desenvolvida uma leitura do livro O pátio das sombras, de Mia Couto,classificado como conto para o público infanto-juvenil, com ilustrações do celebrado artista moçambicanoMalangatana. O objetivo do texto é discutir a presença de elementos da cultura do povo Maconde, do norte de Moçambique, e a forma como Mia Couto coloca em diálogo a tradição cultural e a criação literária, ressignificando aspectos de práticas culturais no âmbito da modernidade. Ao realizar esse procedimento, o autor estabelece uma ponte entre a tradição e o leitor, reafirmando o investimento que tem feito ao longo de sua produção como viajante entre culturas e tradutor de experiências.
\end{abstract}

\begin{abstract}
This article presents a reading of the book O pátio das sombras, by Mia Couto, classified as a short story for children and adolescents, will be developed, with illustrations by the celebrated Mozambican artist Malangatana. The aim of the text is to discuss the presence of elements of the culture of the Maconde people, from northern Mozambique, and the way Mia Couto puts cultural tradition and literary creation in dialogue, re-signifying aspects of cultural practices in the context of modernity. In carrying out this procedure, the author establishes a bridge between tradition and the reader, reaffirming the investment he has made throughout his production as a traveler between cultures and a translator of experiences.
\end{abstract}

Palavras-chave: Mia Couto, tradição, cultura, leitura, ilustração

Keywords: Mia Couto, tradition, culture, reading, illustration

1 Possui Graduação em Língua Portuguesa e Inglesa e respectivas Literaturas pela Universidade do Estado de Mato Grosso (1992), Especialização em
Literatura Brasileira pela Universidade Católica de Minas Gerais - PUC/MG (1996); Mestrado em Letras (Literatura Brasileira) pela Universidade
Federal do Paraná (1999) e Doutorado em Letras (Estudos Comparados de Literaturas de Língua Portuguesa) pela Universidade de São Paulo
(2007). Realizou estágio de doutorado na Universidade de Lisboa (2006). Realizou Estágio de Pós-doutorado na Université Sorbonne-Nouvelle -
Paris 3 (2010-2011). Atualmente é professora Adjunta da Universidade do Estado de Mato Grosso, atuando principalmente nos seguintes temas:
Literatura Comparada, Literaturas Africanas, Literatura, Memória e Política. Coordena o Projeto de pesquisa “A condição provisória do presente:
questões de literatura e política". É integrante do Centro de Pesquisas em Literatura - CEPLIT- UNEMAT, do Programa de Pós-graduação em
Estudos Literários da UNEMAT - PPGEL (Mestrado e Doutorado) e do Programa de Mestrado profissional em Letras - PROFLetras da UNEMAT. 
Um autor conhecido e de caráter se reconhece desde o título do livro. Nele já se insinuam pistas e sinais do que vem depois, antes mesmo de se ler na capa o nome impresso. Esse é o caso de O pátio das sombras, de Mia couto, publicado no quadro de uma Coleção da Escola Portuguesa de Moçambique em 2014 e que ganha edição brasileira em 2018 pela Kapulana. A obra responde a um valoroso projeto de recontar contos da tradição cultural moçambicana, com a participação de dez escritores. Dirigido ao público infanto-juvenil, conforme informações da editora na catalografia da obra, décimo da volume da coleção, o reconto de Mia Couto é construído a partir de um conto do povo Maconde, do norte de Moçambique.

Propostas dessa natureza, como se sabe, são comuns e inscrevem a obra literária nas tradições orais desde as muitas versões Charles Perrault, Irmãos Grimm e Christian Andersen; ou anteriores, como é o caso de obras clássicas como a Odisseiade Homero e da compilação árabe As mil e uma noites. O próprio Mia Couto já participou de um projeto de visitação ao cancioneiro de Chico Buarque, Essa história está diferente, de 2010, criando um conto a partir da canção Olhos nos olhos.

Mas além da tradição enriquecida com experiências sociais que vão solidificando uma gama histórica de acontecimentos da cultura, pode-se ver que os modos de ler se transformam, alterando as histórias e não raro transformando-as em outras narrativas, com diferentes referentes simbólicos. Na origem desse tipo de projeto encontramos a milenar necessidade de narrar que constitui a natureza humana na sua ardilosa fábrica de instrumentos e estratégias para vencer a ideia da morte, do mal e do fim e, ao mesmo tempo, conceber sentidos para a existência.

Nessediapasão, $O$ pátio das sombras pode ser visto numa dupla vertente:a primeira seria a de uma tradição narrativa que remonta a mitos, arquétipos e práticas de releitura numa acepção mais universal da narrativa como enredo da existência e que se presentifica em sistemas literários diferentes. A segunda - e a ordem aqui não é de nível de importância -seriade uma inscrição na cultura que é da ordem da transfiguração da tradição, transfiguração entendida no sentido com que Antonio Candido tingiu o termoem uma entrevista concedida a Fischer e publicada no Zero Hora em 2009 em que, embora estivesse refletindo sobre nacionalismo e crítica na literatura brasileira, alicerçou seu argumento nas negociações entre a tradição e a solução particular de uma literatura, permitindo estender suas premissas para outras literaturas.

A tradição e a transfiguração do real chamam a atenção neste despretensioso livro de Mia Couto porque o reconto, da forma como é lavorado, apresenta-se muito mais do que um artificio narrativo. Ao articular saberes e vivências do mundo moderno com o da ancestralidade e propor um encontro com as tradições, o autor convida crianças e adultos a adentrarem a dimensão simbólica da vida, compartilhada, dialógica, nesse pátio, o pátio das sombras, de sua própria ancestralidade, ou seja, de sua própria humanidade.

A narrativa, que é iniciada com travessão, adianta esse momento de comunhão cultural que se vai experimentar ao fazer contato com o mundo dos antepassados. O leitor de Mia Couto sabe 
que uma das maneiras de ele realizar essa aliança temporal, em que os relógios perdem o sentido e os espaços se diluem sem cataclismas, é estabelecer ininterruptamente trânsitos entre esses tempos e espaços reconfigurados como a dizer que avós e netos, velhos e jovens, marcam apenas o instante individual em que os seres humanos se cruzam na sua efêmera existência. “- Venha avó, venha ajudarnos no campo!" (COUTO, p.5), convida o neto, ao que a avó recusa justificando estar com dores de cabeça.O campo é muito mais que o espaço da lavoura e a avó empenha-se em traduzi-lo ao neto.

Mas em Mia Couto, o passado é veia aberta, de forma clara é fluida, sem pressuposições de resquícios de uma categoria fixa e fechada. O passado é permeável e está continuamente modificando o presente e, por isso mesmo, alterando sua própria consistência, transformando o presente e a si mesmo em algo que não é mais, sem deixar de ser, trilhado por reflexões e relações novas que vão aos poucos condicionando um território de escrita.

A estratégia de visitar o passado, as tradições de povos moçambicanos, estabelecer uma comunicação com o passado tem sido um estado de constância na obra de Mia Couto e em $O$ pátio das sombras, o recontoresulta na matéria consubstanciada de uma tradução.Nele, a forma de apropriação que o autor opera a partir de elementos da cultura tradicional de povos moçambicanos e africanoscumpre até mesmo modificar o adágio popularque assim poderíamos traduzir: de "quem conta um conto aumenta um ponto" para "quem reconta um conto modifica muitos pontos".

Para que o reconto ganhe vida própria - como um conto que modifica muitos pontos -, o autor mantém algumas referências importantes. Uma delas é a do pátio, que aparece no título e está presente no decorrer da narrativa, trazendo o sentido de quintal, espaço de reunião, aberto e de convívio comunitário. Sobre o vocábulo 'pátio', constata-se que está ligado a um espaço público, sem teto, mas ao mesmo tempo privado, pois que compõe uma casa, uma morada. Esse aspecto é de distinta relevância porque a esse elemento, o pátio, liga-se um outro, a importância das sombras despidas de qualquer conotação negativa. Temos então, já no título, uma matéria simbólica delimitada que proporciona ambientação adequada à confluência rítmica e fluente entre a tradição e a modernidade.

Um estudo fôlego sobre o escuro, da noite, da morte, do medo e das sombras na obra de Mia Couto ainda está por ser feito no Brasil, seja porque são presença constante em sua obra narrativa desde os romances até os contos, seja porque há uma mitologia própria construída pelo autor que constitui espaços cifrados do mundo exterior, da política, das distopias contemporâneas - e que em sua poética empenha-se em desvelar -, mas também porque se projeta uma forma inusual de transpor o mundo da vida para o mundo da escrita em que as palavras e as imagens são despidas de suas conotações iniciais, alcançando um patamar poético que as traduzem de forma positiva.

No caso de $O$ pátio das sombras, é possível reconhecer um espectro de tipologias que deriva dessas temáticas e que informa uma perspectiva nova sobre a vida moderna, em geral, urbana, e sobre os mitos tradicionais, em geral relacionados ao campo. O pátio das sombras para o menino e para a avó desponta como um espaço de conhecimento, de compreensão do mundo e compartilhamento da 
memória cultural de seu povo. O encontro libertador que ocorre nesse pátio - nesse jardim-quintal -, restaura o sonho do menino que agora, em contato com a morte do pai, redimensiona os sentidos da morte e da vida.

Nesse sentido, a narrativa apresenta um movimento cíclico em que a ordem do texto acompanha a ordem da natureza e da vida e cada dia traz um acontecimento novo, uma nova aprendizagem para o menino. O tempo da colheita comanda esse movimento e é para lá que seguem todos da aldeia quando chega o momento de colher, antes "que os macacos e os porcos selvagens atacassem a machamba (COUTO, p. 7). Um primeiro suspense é criado quando a avó explica aos mais jovens que não irá porque está com muita dor de cabeça e quando, em seguida, da machamba, ouvem estranhos barulhos. Encontramos na narrativa, nesse ponto, o mergulho do narrador e das personagens no terreno das possibilidades múltiplas que deixam de se referenciar no mundo lógico e rotineiro da vida objetiva para alçar o tempo flexível, intercambiável e mítico, fazendo-o às avessas:

Um rastulhar no mato o trouxe para a realidade. Era a avó que emergia da floresta para se sentar ao seu lado. A velha sentou-se no parapeito do poço e disse ao neto que lhe ia contar um segredo. Então, ela confessou que os filhos mortos moravam vivos dentro da sua cabeça. À medida que os filhos iam morrendo a cabeça começava a tornar-se muito grande. E começou-lhe a pesar muito. Foi a partir daquele momento que deixou de poder sair de casa. Quando ela ficava só, os habitantes da sua cabeça eclodiam: raparigas, mulheres com filhos, homens, rapazes. E festejavam a vida no pátio da casa (COUTO, p. 14).

Ao encontrar-se com a avó, o menino é trazido para a realidade mas a realidade se desintegra e retoma sendas de outras realidades, reafirmando o gosto de Mia Couto pela recomposição da visão cósmica por suas personagens. Desse modo, além do tempo da colheita e da organização circular do texto - (a velha estava debruçada sobre si mesma; reincidência de início de parágrafos com a construçãoNo dia seguinte...; O regresso dos mortos, os círculos concêntricos formados na água do poço quando atiradas pedras), há um objeto mágico no texto que funciona como um marcador do ciclo e da retomada e que se deixa visualizar pela palavra-imagem que corporifica esse movimento circular: a pulseira.

A palavra que indica circularidade, além de compor uma simbologia da ligação do menino com seus ancestrais, é citada de forma direta uma dezena de vezes no texto. Com esse símbolo de ligação e de circularidade, a narrativa é conduzida para uma outra esfera, configurada na matéria ajustável à forma, que é a água no poço. A presença da água é um elemento que traduz uma simbologia rica e variada na obra de Mia Couto e, neste livro, principalmente, traduz-se numa súmula exemplar das ideias de renovação, de profundidade e de perspectiva que o autor utiliza para tratar da distensão 
simbólica da vida. O poço aparece como a imagem de uma paz imperturbada, na forma da água estagnada, como se o tempo estivesse suspenso na distração da água imóvel que o preenche. Além disso, poço é o continente que comporta a semântica deprofundidade, escuridão, invisibilidade, medo, segredo, desconhecido e que, ao mesmo tempo, represa a água que significa renovação, mudança e vida.

Não cabe no âmbito do presente estudo abordagens sobre a fenomenologia da água, só para lembrarmos os inspiradores textos de Gaston Bachelard, mas não se pode negar que como elemento imagético, na organização circular da obra, a água ocupa um lugar importante para os sentidos que buscamos apreender do texto. A água é, de fato, um dos elementos da natureza mais importantes na obra de Mia Couto, como lembra Tania Macêdo, lendo A chuva pasmada:

Mas se a raiz, a terra, a estrada e espaço onde o frangipani se fixa indiciam o solo pátrio e dessa maneira presentificam-se nas produções de Couto, não podemos deixar à margem que a água (apresentada no título de seu primeiro livro como orvalho), é também um tema caro ao autor e, sob a forma de chuva, de rios, de mar, ou do orvalho, a água transborda dos textos de Mia Couto, simbolizando, entre outros aspectos, o devir e a passagem inexorável do tempo, bem como o recomeçar (MACÊDO, p. 348).

A presença desse elemento da natureza na obra do autor é matriz de metáforas das mais variadas e a estudiosa nos apresenta seus vértices matriciais. Os desdobramentos desse código artístico, fenomenológico, são mais uma vez a liquidez da experiência naquilo que ela tem de mais mutante, que é sua matéria transfiguradora.

Caminhando sobre os muros desse pátio das sombras, e buscando uma aproximação mais efetiva com elementos internos que constituem parte da cosmogonia da obra, ainda encontra-se a composição formal do livro: ilustrações postas em diálogo; palavra do autor sobre o porquê escolheu o conto Maconde; o conto mesmo, na forma original; palavra do autor sobre o porquê realizou alterações no enredo e na trama do conto de origem.

Todos esses aspectos, que são externos ao texto e que figuram como artifícios em forma de posfácio, explicações editoriais, informações complementares, passam a ser internos, como nos ensina Antonio Candido, na medida em que entram na composição da narrativa, constituindo instâncias textuais complexas e convocando diálogos culturais que ultrapassam o espaço da ficção.

Exemplo disso é a referência feita por Célia Ruiz, em resenha da obra em 2018, da dança mapiko, uma das principais danças do povo Maconde, especialmente de Cabo Delgado, e que aparece no final do conto, quando todos dançam no pátio. Pode-se afirmar que há uma conversão dessa dança, uma vez que o menino, ao encontrar-se com o pai, recebe dele ensinamentos - e a pulseira -, como o 
que "os mortos que são lembrados não morrem nunca".

Se o mapiko tradicional, que ainda é praticado no norte de Moçambique, se caracteriza sobretudo por ser um rito de iniciação masculina, vedado às mulheres, Mia Couto faz uma conversão: o pai dança com o filho, mas a avó também, além de que o sacrifício pela feitiçaria é transformado em preservação do velho como portador de sabedoria a ser repassada ao neto. Ruiz lembra que "em épocas remotas, na sociedade Maconde ainda matrilinear, as mulheres eram muito poderosas, sendo responsáveis por decisões políticas e dominando a magia e as poções”(2018, p.). Uma das afirmações eventuais que podemos colher na escuta de $O$ pátio das sombras, quanto à avó feiticeira da narrativa original, é que a história é feita por homens e mulheres e a eles cabem o arbítrio. Se a história pode ser modificada pela ação humana, Mia Couto lança-se na sua investidura pela liberdade, e representa essa avó como alguém que possui conhecimentos a serem ensinados aos mais jovens e que, por isso, deve ser celebrada e participar da vida, assim como os mortos e não sacrificada ou banida. A dança no pátio é um acontecimento humano dessa natureza, daí haver muito sentido no que Célia Ruiz assinala:

A festa dos familiares falecidos, descrita na narrativa, faz referência a uma manifestação cultural de Moçambique, o Mapiko. Na tradição do povo maconde, um homem mascarado dança ao som de batuque e cantos tradicionais, estabelecendo um elo mágico e sobrenatural com o mundo dos mortos. A identidade do dançarino fica em segredo, pois acredita-se que ali não é o homem que dança, mas sim um espírito. Em "Pátio das Sombras", não há referência a máscaras, mas a festa e a dança dos seres em estado de êxtase e alegria lembram a celebração (RUIZ, 2018, p.212).

Embora não haja referências a máscaras, podemos compreender um aspecto que ocupa um lugar importante na composição da obra: o lugar da ilustração. Nas obras escritas para o público infantil a ilustração ocupa um lugar de relevo. Sabemos que na medida em que as obras vão sendo destinadas a um público mais adulto tendem a ir ampliando o espaço do texto até desaparecerem figuras, imagens e ilustrações. Na literatura infanto-juvenil, em geral, é parte da história, como a música é parte do filme e a dança se integra com perfeição ao teatro. Nem sempre uma obra é composta ombro a ombro, mas há muitos casos de parcerias entre escritores e ilustradores que funcionam muito bem e que o aprimoramento gráfico das editoras tem sabido explorar com ótimos resultados.

No caso de $O$ pátio das sombras, o que encontramos, no entanto, não são ilustrações feitas expressamente para um livro infantil ou juvenil, uma vez que a primeira edição do livro é de 2014 em Portugal quando Malangatana já tinha falecido (em janeiro de 2011) e, ao que consta, a coleção Contos de Moçambique foi concebida após sua morte.

Não se pode também esquecer que, pela tradição literária, a literatura para crianças e jovens nasce vinculada a uma necessidade educativa e a associação da linguagem verbal à visual foi explorada como uma maneira de reter a atenção da criança e obter êxito na missão pedagogizanteque propunha. 
Ao analisar vários livros infantis pode-se perceber que a associação estética entre texto e ilustração, no entanto, nem sempre se dá de forma equilibrada, resultando em muitos casos que a ilustração prevalece sobre o texto. Em um livro de literatura, mesmo a ilustração sendo constituinte e mesmo determinante de sentidos, nunca podemos esquecer que o texto literário continua sendo aquele que exige cuidado com a linguagem e labor estético. E com isso, pode-se enfrentar a questão da qualidade do texto, tão à tona quando se trata da categorização da literatura produzida e publicada como sendo para o público infantil e jovem.

Em se tratando de $O$ pátio das sombras, o livro é uma obra com ilustração e não uma obra ilustrada, como caracteriza Linden (2006). É a arte de nanquim do celebrado artista moçambicano Malangatana Valente Ngwenya, quando suas pinturas já tinham se espalhado pelo mundo e se tornado conhecidas pelo uso de cores vibrantes e pelos traços dramáticos em que se estruturam. No entanto, a ilustração cumpre com justiça seu papel de ilustração, atendendo ao clima de mistério e de curiosidade construído pelo narrador que sabe conduzir a história dando a medida do movimento e presidindo a narrativa para prender a atenção do leitor, por meio de avanços, suspensões e recuos, operações que garantem a manutenção do interesse. Esses movimentos da narrativa, somados à sua estrutura circular e cíclica, são muito bem sintonizados com o universo simbólico traduzido pelas linhas coloridas e dramáticas de Malangatana, como podemos observar a partir da ilustração inicial na primeira capa:

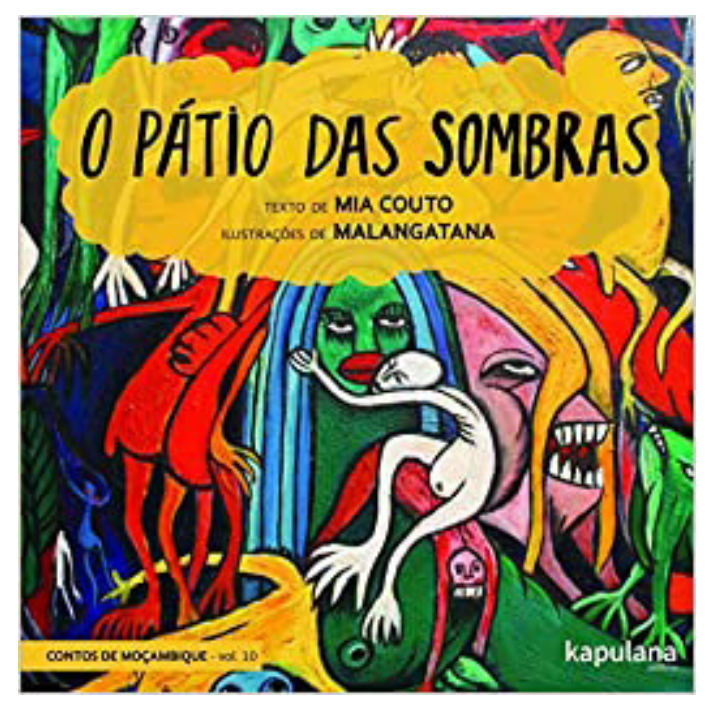

Imagem 1: capa de O Pátio das Sombras, de Mia Couto. Fonte: acervo pessoal da autora

Além do movimento, as ilustrações acompanham o ritmo da narrativa e o controle do narrador sobre a matéria narradaque alcançam o suspense e apresenta o desenlace da história. Isso se dá quando o menino aprende que os mortos, quando são amados e lembrados, de fato não morrem. $\mathrm{O}$ aprendizado do menino na cadência da dança no pátio, pelas mãos da avó e pelo encontro com o pai, não é exatamente um aprendizado, mas a compreensão e a experiência. O menino acessa algo do que 
ele fazia parte, mas ainda não tinha compreendido. Esse ritmo é pautado pelas ilustrações coloridas e em preto e branco em que seres híbridos, ou realidades híbridas, se deslocam e se reconfiguram no processo de travessia do menino para um mundo adulto, de verticalidade da experiência. É o rito de passagem, com a dança do mapiko, como interpreta Ruiz. A travessia celebrada por Mia Couto em tantos outros textos, como por exemplo Nas águas do tempo ou A casa marinha que compõem a propositura do autor em desestabilizar fronteiras e muros que separam os vivos dos mortos, os velhos dos jovens ou os seres humanos da natureza, é reeditada nesse reconto em toda sua magnitude.O mapiko se cumpre pela narrativa enquanto se integra, no jogo estético das ilustrações, à iniciação do menino.

Nesse sentido, o livro não é apenas para crianças, dada a complexidade do que é abordado na sua narrativa. Num texto de 1924 sobre um colecionador de livros infantis, Karl Hobrecker, Walter Benjamin nos dá uma apreciação sobre a literatura dirigida para crianças que pode fazer sentido ainda hoje.

A atual literatura romanesca juvenil, criação sem raízes, por onde circula uma seiva melancólica, nasceu no solo de um preconceito inteiramente moderno. Trata-se do preconceito segundo o qual as crianças são seres tão diferentes de nós, com uma existência tão incomensurável à nossa, que precisamos ser particularmente inventivos se quisermos distraí-las. No entanto nada é mais ocioso que a tentativa febril de produzir objetos - material ilustrativo, brinquedos ou livros - supostamente apropriados às crianças.” (BENJAMIN, p. 237)

Dessas considerações de Benjamin podemos depreender duas coisas, considerando que ele está imbuído de um trabalho de historiografia. A primeira é que o bom livro interessa a qualquer público. E a segunda é que não existe livro difícil, a criança só espera que o livro não a trate como um ser incapaz, desprovido de inteligência e sem criatividade, pois para Walter Benjamin,

a criança exige dos adultos explicações claras e inteligíveis, mas não explicações infantis, e muito menos as que os adultos concebem como tais. A criança aceita perfeitamente coisas sérias, mesmo as mais abstratas e pesadas, desde que sejam honestas e espontâneas e, por isso, algo pode ser feito a favor daqueles velhos textos" (BENJAMIN, p. 236-7).

Ao tratar do livro infantil no século XVIII como um dos únicos lugares onde poderia haver, no iluminismo, "esse mundo de cores, em sua ostentação complacente" (p.239), Benjamin contribui para 
restituir a esse gênero uma qualificação positiva que, sendo honesto, manterá o interesse de qualquer leitor independente da idade. Nesse sentido, em Mia Couto: lugares da infância, Gregorin, lendo obras infantis de Mia Couto, observa que

Temos hoje, uma produção literária (artística) para as crianças que não nasce apenas da necessidade de se transformar em recurso pedagógico, mas cujas principais funções são o lúdico, o catártico e o libertador, além do pragmático e do cognitivo (GREGORIN, p. 345).

Segundo o autor, a multiplicidade de vozes que ganham espaço na literatura de Mia Couto demonstra que sua produção destinada para o público infantil e juvenil se localiza muito além de categorias reducionistas de gênero literário ou de definição de leitores, mas reivindica-se como uma "literatura que busque as manifestações artísticas e demonstre o imaginário das sociedades" (p. 344$5)$.

O pátio das sombras, assim, apresenta-se como um conto que, sendo curto, atinge a complexa organização da sociedade moçambicana, revelando uma parte inexplorada das práticas sociais do povo Maconde, no que se refere às suas tradições e à suas entradas na modernidade. Sendo um conto que, editorialmente, se destina a crianças e jovens, ultrapassa deferências desse público e entra no campo de interesse de todos que apreciam um texto literário de qualidade estética indubitável. $\mathrm{O}$ narrador e as personagens compartilham experiências e os territórios de trocas se ampliam no encontro da avó com o neto, dos vivos com os mortos e, no plano artístico, do conto popular com a escrita transfiguradora de Mia Couto.

Uma parte do mundo sempre permanece, mas uma outra se transforma e ao se transformar modifica a substância daquela que permaneceu. O menino foi iniciado. Mas é apenas um recomeço. A água represada, no fundo de um poço, onde a escuridão e o medo poderiam se alojar, nada mais edifica que a experiência do menino, da avó e da comunidade, pois o menino é a parte que se transforma. À beira desse poço o neto chora, chora tristezas que nem sabia que tinha dentro de si. Mas a avó também chora. E a água, salgada da lágrima, reúne os tempos e celebra o ciclo da vida.

\section{Referências:}

CANDIDO, Antonio. A literatura é uma transfiguração da realidade. Entrevista a Luís Augusto Fischer, Homero Araújo, Ian Alexander, Marcelo Frizon e Tatiana Tavares. Belo Horizonte: Revista O eixo e a roda: v. 20, n. 1, 2011 (p.156-162)

COUTO, Mia. O pátio das sombras. Ilustrações de Malangatana, vol. 10. In: Contos de Moçambique, São Paulo: 
Kapulana, 2018

DELUMEAU, Jean. História do medo no ocidente: 1300-1800 - uma cidade sitiada. São Paulo: Companhia das Letras, 1989.

LINDEN, Sophie van der. Para ler o livro ilustrado. Trad. de Dorothée de Bruchard. São Paulo: Cosac Naify, 2011.

BENJAMIN, Walter. "Livros infantis antigos e esquecidos". In: BENJAMIN, Walter. Magia e técnica, arte e política: ensaios sobre literatura e história da cultura. São Paulo: Brasiliense, 1985.

CAVACAS, F.; CHAVES, R. e MACÊDO, Tania (Organizadoras). Mia Couto: um convite à diferença. São Paulo: Humanitas, 2013.

GREGORIN FILHO, José Nicolau. Mia Couto: lugares da infância. In: CAVACAS, F.; CHAVES, R. e MACÊDO, Tania (Organizadoras). Mia Couto: um convite à diferença. São Paulo: Humanitas, 2013. (p.337-346)

MACÊDO, Tania. "Provocações: uma leitura de A chuva pasmada". In: CAVACAS, F.; CHAVES, R. e MACÊDO, Tania (Organizadoras). Mia Couto: um convite à diferença. São Paulo: Humanitas, 2013. (p. 347-354)

RUIZ, Regina Célia. (RESENHA) "O pátio das sombras: a representação da morte na releitura de Mia Couto". In: Revista Literartes, n. 9 | 2018. (p.209-214).Acessado em 28 de abril de 2020.https://www.revistas.usp.br/literartes/ article/view/153210/149933 